\title{
Catalytic Conversion of Anisole: Evidence of Oxygen Removal in Reactions with Hydrogen
}

\author{
Ron C. Runnebaum • Tarit Nimmanwudipong • \\ David E. Block • Bruce C. Gates
}

Received: 23 September 2010/Accepted: 18 November 2010/Published online: 14 December 2010

(C) The Author(s) 2011. This article is published with open access at Springerlink.com

\begin{abstract}
The conversion of anisole, a prototypical biooil compound, was catalyzed by $\mathrm{Pt} / \mathrm{Al}_{2} \mathrm{O}_{3}$ in the presence of $\mathrm{H}_{2}$ at $573 \mathrm{~K}$, with the selectivity for $\mathrm{C}-\mathrm{O}$ bond breaking approximately matching that for ring hydrogenation; these reactions were accompanied by methyl group transfers matching those in the conversion catalyzed by HY zeolite.
\end{abstract}

Keywords Anisole - Zeolite Y · Supported platinum . Transalkylation $\cdot$ Hydrodeoxygenation

\section{Introduction}

Plant biomass is a potentially valuable renewable source of fuels and chemicals. Lignocellulose can be rapidly transformed into liquids by pyrolysis, giving "bio-oil," but the high oxygen content leads to immiscibility with fossil fuels, instability, and corrosion [1-3]. Bio-oils typically contain several hundred compounds $[4,5]$, and an understanding of the reaction networks in their catalytic upgrading is limited; even information characterizing the upgrading of individual bio-oil compounds is scarce [610]. Our approach to begin unravelling this chemistry, and specifically to understand oxygen removal reactions, was to investigate the conversion of a bio-oil compound, anisole, chosen as a prototype because it has both an ether linkage

R. C. Runnebaum · T. Nimmanwudipong

D. E. Block · B. C. Gates ( $\triangle)$

Department of Chemical Engineering and Materials Science,

University of California, Davis, CA 95616, USA

e-mail: bcgates@ucdavis.edu

D. E. Block

Department of Viticulture and Enology, University of California, Davis, CA 95616, USA and an aromatic ring. Reactions were catalyzed by a solid acid (HY zeolite, Zeolyst CBV 720) and separately by a catalyst consisting of a metal dispersed on an acidic support $\left(\mathrm{Pt} / \mathrm{Al}_{2} \mathrm{O}_{3}\right.$, Sigma-Aldrich, $\left.1 \% \mathrm{wt} \mathrm{Pt}\right)$. The goal of the research was to develop detailed reaction networks, characterized by numerous connected pathways, for the conversion of anisole with catalysts representing these two important classes of catalysts.

\section{Experimental}

Catalytic reactions were carried out in a once-through packed-bed flow reactor under the following conditions, with liquid anisole (methoxybenzene, Sigma-Aldrich, 99.8\%) vaporized into a flowing gas stream: catalyst mass 4.1-401.5 mg, temperature $573 \mathrm{~K}$, pressure $140 \mathrm{kPa}$, anisole liquid flow rate $0.03 \mathrm{~mL} \mathrm{~min}^{-1}$, gas feed flow rate $100 \mathrm{~mL} \mathrm{~min}^{-1}$ (as pure $\mathrm{N}_{2}$ in experiments with $\mathrm{HY}$ zeolite and as $30 \% \mathrm{H}_{2} / 70 \% \mathrm{~N}_{2}$ in experiments with $\mathrm{Pt} / \mathrm{Al}_{2} \mathrm{O}_{3}$ ). Each catalyst powder was diluted with particles of inert, nonporous $\alpha-\mathrm{Al}_{2} \mathrm{O}_{3}$. The product gas stream was condensed at 285-288 K. Uncondensed gases and condensate samples collected periodically were analyzed by gas chromatography and gas chromatography/mass spectrometry.

\section{Results}

Dozens of products were observed in the conversions with each catalyst. Significant catalyst deactivation, characterized by a $50 \%$ reduction in conversion within $1 \mathrm{~h}$ on stream, was observed with $\mathrm{HY}$ zeolite; the $\mathrm{Pt} / \mathrm{Al}_{2} \mathrm{O}_{3}$ catalyst working in the presence of $\mathrm{H}_{2}$ was much more stable. Selectivities to major and minor products at low initial 
Table 1 Products of conversion of anisole catalyzed by $\mathrm{Pt} / \mathrm{Al}_{2} \mathrm{O}_{3}$ and by HY zeolite (liquid product streams)

\begin{tabular}{lll}
\hline Product & $\begin{array}{l}\text { Selectivity to } \\
\text { product in reaction } \\
\text { catalyzed } \\
\text { by Pt/ } \mathrm{Al}_{2} \mathrm{O}_{3}\end{array}$ & $\begin{array}{l}\text { Selectivity to } \\
\text { product in reaction } \\
\text { catalyzed } \\
\text { by HY zeolite }\end{array}$ \\
\hline Phenol & 0.65 & 0.60 \\
2-Methylphenol & 0.15 & 0.11 \\
Benzene & 0.044 & - \\
Cyclohexanone & 0.033 & - \\
2,6-Dimethylphenol & 0.024 & 0.011 \\
2-Methylanisole & 0.0077 & 0.13 \\
4-Methylphenol & 0.0022 & 0.045 \\
4-Methylanisole & 0.0013 & 0.15 \\
\hline
\end{tabular}

Data were extrapolated to zero time on stream, and thus represent approximate initial selectivities determined at a weight hourly space velocity of 18 ( $\mathrm{g}$ of reactant)/(g of catalyst $\cdot \mathrm{h}$ ), a pressure of $140 \mathrm{kPa}$, and a temperature of $573 \mathrm{~K}$. Selectivity is defined as yield [mol product formed $/ \mathrm{mol}$ of organic reactant fed]/conversion [mol of organic reactant consumed/mol of organic reactant fed]. In the experiments with the $\mathrm{Pt} / \mathrm{Al}_{2} \mathrm{O}_{3}$ catalyst, the feed molar ratio of $\mathrm{H}_{2}$ to the organic reactant was 2400

conversions ( 0.14 for $\mathrm{Pt} / \mathrm{Al}_{2} \mathrm{O}_{3}$ and 0.16 for $\mathrm{HY}$ zeolite) are summarized in Table 1; these data represent extrapolations to zero time on stream and therefore initial catalyst performance, prior to significant deactivation.

The most abundant products of the conversion catalyzed by HY zeolite were phenol, methylanisoles, and methylphenols; less abundant products included dimethylanisoles and dimethylphenols. The substitution at the 2- and 4positions on the aromatic ring is consistent with the kinetically determined substitution preference of aromatic ethers and aromatic alcohols [11]. Trace products included those with additional methyl-group substitutions on the aromatic ring (observed with each catalyst) and hydrogenation products, such as cyclohexane, which were also formed with $\mathrm{Pt} / \mathrm{Al}_{2} \mathrm{O}_{3}$ in the presence of $\mathrm{H}_{2}$.

The most abundant products of the reactions catalyzed by $\mathrm{Pt} / \mathrm{Al}_{2} \mathrm{O}_{3}$ were phenol, 2-methylphenol, and benzene; less abundant products included water, methane, methanol, 2-methylanisole, and 4-methylanisole. The appearance of cyclohexanone, for example, indicates hydrogenation of the aromatic ring [12].

Thus, an important class of reaction, observed for both catalysts, is methyl group transfer. Hydrogenolysis, hydrogenation, and hydrodeoxygenation were also observed in the conversion catalyzed by $\mathrm{Pt} / \mathrm{Al}_{2} \mathrm{O}_{3}$ in the presence of $\mathrm{H}_{2}$.

Selectivity versus conversion plots (e.g., Fig. 1) were used to identify products as primary or not $[13,14]$ (these designations are empirical, falling short, for example, of providing information about intermediates that were too

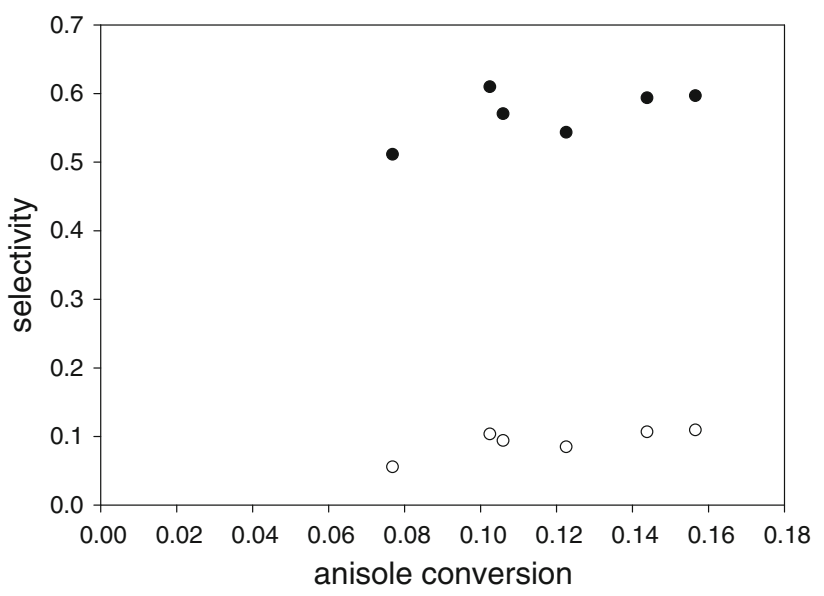

Fig. 1 Selectivity for the formation of phenol (closed circles) and 2methylphenol (open circles) in the conversion of anisole catalyzed by HY zeolite at $573 \mathrm{~K}$. Data for each product were fitted with a straight line and extrapolated to zero conversion; intercepts of regression lines significantly different from zero selectivity at zero conversion (analyzed with $95 \%$ confidence limits) indicate primary products, in this case phenol, and those not significantly different from zero (analyzed with $95 \%$ confidence limits) are considered non-primary, in this case 2-methylphenol

reactive to be detected). The selectivity-conversion data observed for anisole conversion catalyzed by HY zeolite (Figs. 1, 2) indicate that phenol, 2-methylanisole, 4-methylanisole, and 2,6-dimethylphenol (data not shown) were primary products and that 2-methylphenol and 4-methylphenol (data not shown) were non-primary products. Benzene and cyclohexanone were not observed.

On the basis of the data showing that methyl group transfer (transalkylation) is the predominant class of reaction and a primary reaction in the formation of phenol, 2-methylanisole, and 4-methylanisole in the conversion catalyzed by HY zeolite, we infer the qualitative reaction network shown in Fig. 3. For simplicity, the source of the methyl group is not always shown in the reaction network.

The selectivity-conversion data observed for anisole conversion catalyzed by $\mathrm{Pt} / \mathrm{Al}_{2} \mathrm{O}_{3}$ (Figs. 4, 5) in the presence of $\mathrm{H}_{2}$ indicate that phenol, 2-methylphenol, and 4-methylphenol (data not shown) were primary products and that benzene, cyclohexanone, 2- and 4-methylanisole, and 2,6-dimethylphenol (data not shown) were non-primary products.

Presuming that methyl group transfer, hydrodeoxygenation, and hydrogenation are the important reaction classes, and by recognizing which compounds were primary products, we inferred the reaction network of Fig. 6 for anisole conversion catalyzed by $\mathrm{Pt} / \mathrm{Al}_{2} \mathrm{O}_{3}$ in the presence of $\mathrm{H}_{2}$.

The data characterizing the conversion of anisole catalyzed by $\mathrm{Pt} / \mathrm{Al}_{2} \mathrm{O}_{3}$ are represented satisfactorily by firstorder kinetics (Fig. 7). The pseudo first-order rate constant for the overall disappearance of anisole was found to be 


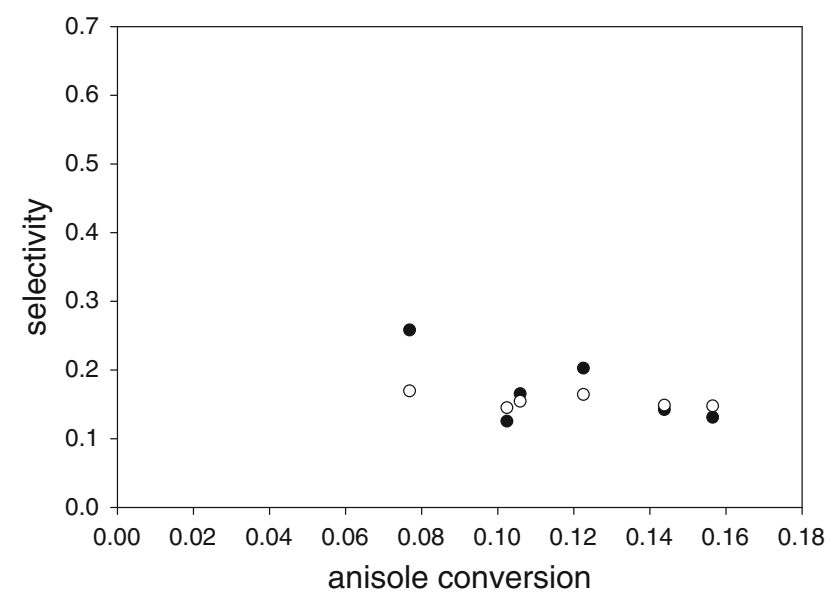

Fig. 2 Selectivity for the formation of 2-methylanisole (closed circles) and 4-methylanisole (open circles) in the conversion of anisole catalyzed by HY zeolite; conditions are stated in the text. Data for each product were fitted with a straight line and extrapolated to zero conversion; intercepts significantly different from zero selectivity at zero conversion (analyzed with $95 \%$ confidence limits) indicate primary products, in this case both 2-methylanisole and 4-methylanisole, and those not significantly different from zero are considered to be evidence of non-primary products

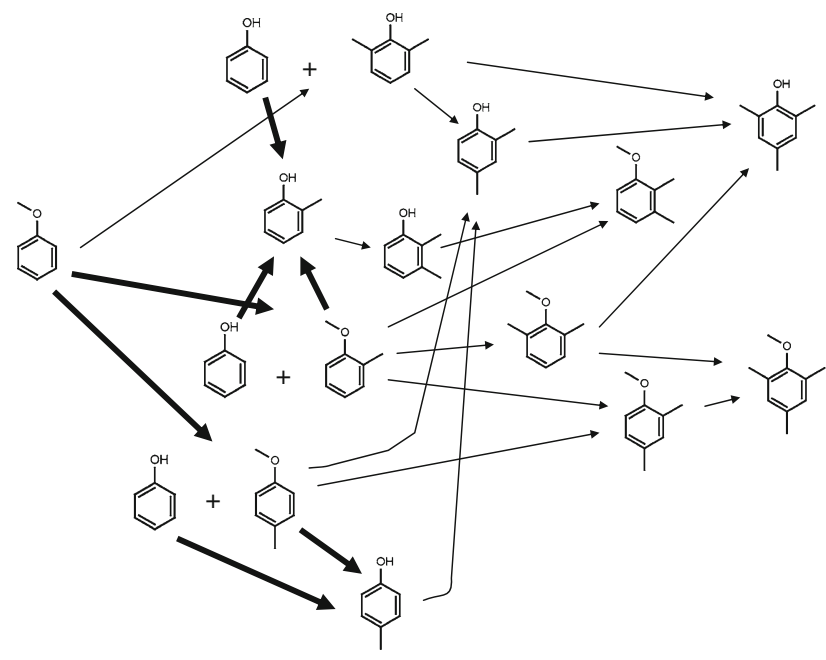

Fig. 3 Reaction network for the conversion of anisole catalyzed by HY zeolite at $573 \mathrm{~K}$. Reactions are postulated on the basis of the products identified, including trace compounds, and their formation as a result of possible methyl group transfer reactions. Bold arrows show the reactions that are kinetically most significant (with the width of the arrow denoting a rough measure of rate; the wider the arrow, the faster the reaction)

$19 \mathrm{~L}$ ( $\mathrm{g}$ of catalyst $\cdot \mathrm{h}$ ) under the conditions stated in the caption of Fig. 6. Selectivities to benzene relative to cyclohexanone indicate that the rate of hydrogenolysis of the $\mathrm{C}-\mathrm{O}$ bond approximately matched that of hydrogenation of the aromatic ring at low conversions and at the low pressure of these experiments.

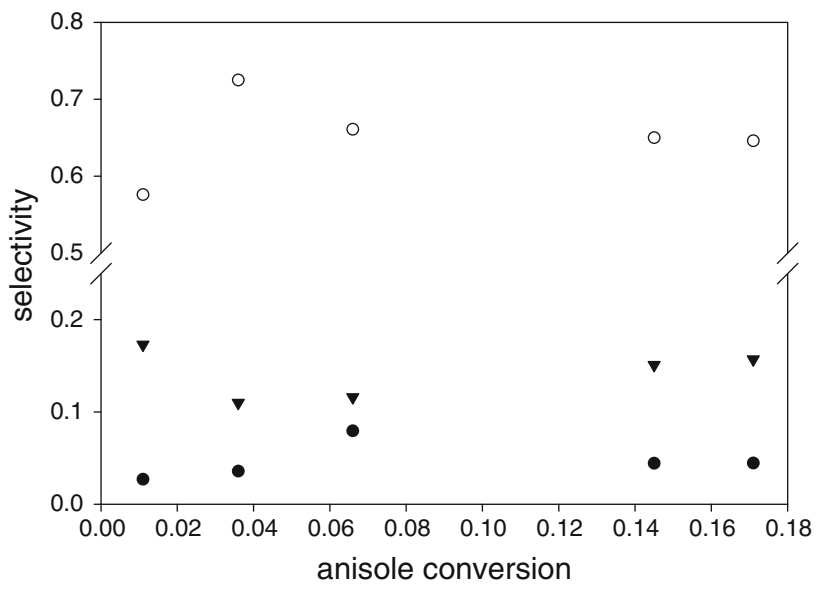

Fig. 4 Selectivity for the formation of several products in the conversion of anisole catalyzed by $\mathrm{Pt} / \mathrm{Al}_{2} \mathrm{O}_{3}$ in the presence of $\mathrm{H}_{2}$ at $573 \mathrm{~K}$. Data for each product were fitted with a straight line and analyzed with $95 \%$ confidence limits as indicated in the caption of Fig. 1; primary products in this case are phenol (open circles) and 2-methylphenol (closed triangles); benzene (closed circles) is a nonprimary product

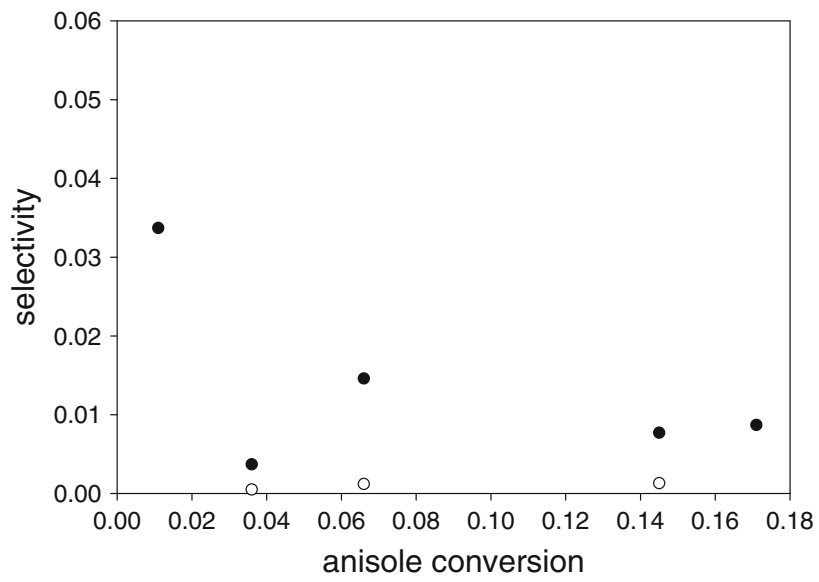

Fig. 5 Selectivity for the formation of 2-methylanisole (closed circles) and cyclohexanone (open circles) in the conversion of anisole catalyzed by $\mathrm{Pt} / \mathrm{Al}_{2} \mathrm{O}_{3}$; conditions are stated in the text. Data for each product were fitted with a straight line and extrapolated to zero conversion; intercepts significantly different from zero selectivity at zero conversion (analyzed with $95 \%$ confidence limits) indicate primary products, and those not significantly different from zero (analyzed with $95 \%$ confidence limits) are considered to be evidence of non-primary products, in this case 2-methylanisole and cyclohexanone

\section{Discussion}

The reaction network of Fig. 3 accounts for major, minor, and trace products; it contains more detail than the reported reaction network proposed for conversion of anisole catalyzed by the zeolite HZSM-5 [6] and is broadly consistent with it. Individual compounds produced with HZSM-5 and not identified in our work include 3-methylphenol and 


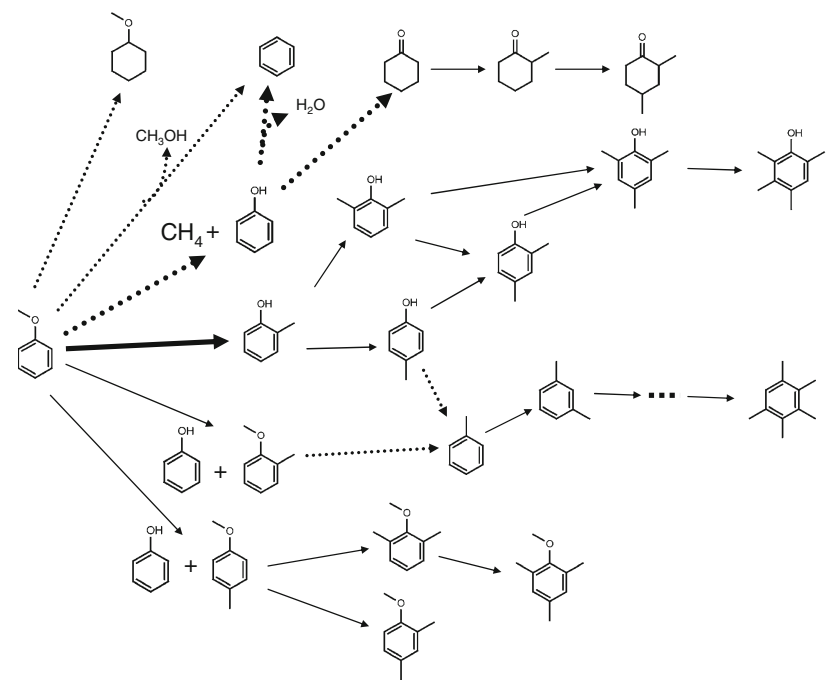

Fig. 6 Reaction network for the conversion of anisole and hydrogen catalyzed by $\mathrm{Pt} / \mathrm{Al}_{2} \mathrm{O}_{3}$ at $573 \mathrm{~K}$. Hydrogenation/hydrodeoxygenation reactions are represented by dotted lines and methyl group transfer reactions by solid lines. $\mathrm{H}_{2}$ as a reactant is omitted for simplicity (designation of arrows as in Fig. 3)

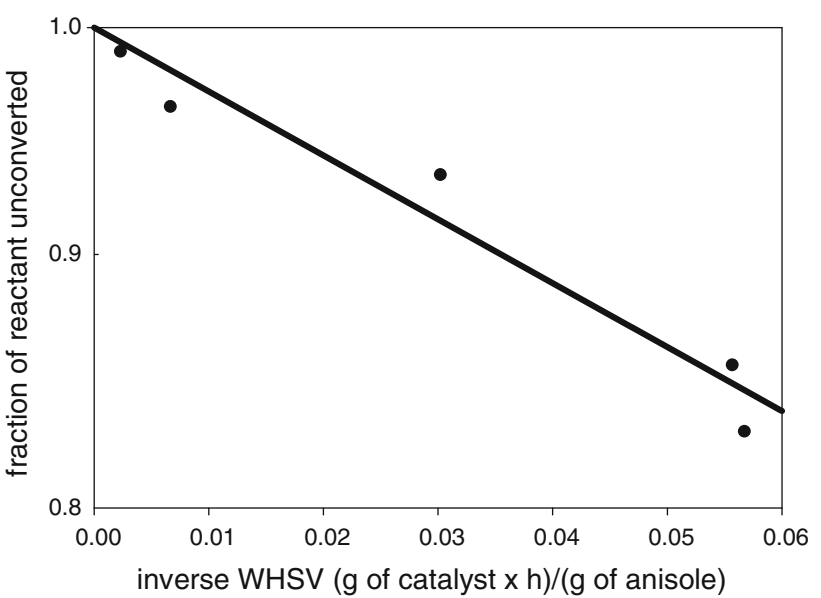

Fig. 7 Demonstration of first-order kinetics of overall conversion of anisole catalyzed by $\mathrm{Pt} / \mathrm{Al}_{2} \mathrm{O}_{3}$ under conditions stated in text

methane, possibly indicating the higher reaction temperature $(673 \mathrm{~K})$ or higher inverse space velocity in the reported work.

Similarly, the reaction network of Fig. 6 accounts for the major, minor, and trace products in the reactions catalyzed by $\mathrm{Pt} / \mathrm{Al}_{2} \mathrm{O}_{3}$, and, again, the detail markedly exceeds than of any comparable reaction network including catalytic hydrodeoxygenation. A comparison of Figs. 3, 6 shows that primary products formed in the presence of one catalyst (e.g., 2-methylphenol) are not necessarily primary products formed in the presence of the other catalyst. The low selectivity to benzene relative to that of products resulting from methyl group transfers suggests that higher concentrations of $\mathrm{H}_{2}$ (and high pressures) will be required to achieve acceptable yields and selectivities for oxygen removal.

\section{Conclusions}

In the conversion of anisole catalyzed by $\mathrm{Pt} / \mathrm{Al}_{2} \mathrm{O}_{3}$ and by HY zeolite, methyl group transfers were found to be kinetically significant reactions, and when the catalyst was $\mathrm{Pt} / \mathrm{Al}_{2} \mathrm{O}_{3}$ used in the presence of $\mathrm{H}_{2}$, the conversion was accompanied by products of $\mathrm{C}-\mathrm{O}$ bond-breaking and hydrogenation reactions. Data such as those reported here provide a starting point for predicting the conversion of bio-oils, specifically for removal of oxygen and upgrading of fuel properties.

Acknowledgments Financial support for this work was provided by Chevron Technology Ventures, a division of Chevron USA, Inc. An Agilent Technologies Foundation Research Project Gift provided a GC7890 Refinery Gas Analyser.

Open Access This article is distributed under the terms of the Creative Commons Attribution Noncommercial License which permits any noncommercial use, distribution, and reproduction in any medium, provided the original author(s) and source are credited.

\section{References}

1. Huber GW, Iborra S, Corma A (2006) Chem Rev 106:4044

2. Mohan D, Pittman CU, Steele PH (2006) Energy Fuels 20:848

3. Stöcker S (2008) Angew Chem Int Ed Engl 47:9200

4. Branca C, Giudicianni G, DiBlasi C (2003) Ind Eng Chem Res 42:3190

5. Milne T, Agblevor F, Davis M, Deutch S, Johnson D (1997) In: Bridgwater AV, Boocock DGB (eds) Developments in thermal biomass conversion. Blackie, London, pp 409-424

6. Zhu X, Mallinson RG, Resasco DE (2010) Appl Catal A 379:172

7. Hong D-Y, Miller SJ, Agrawal PK, Jones C (2010) Chem Commun 46:1038

8. Gayubo AG, Aguayo AT, Atutxa A, Aguado R, Bilbao J (2004) Ind Eng Chem Res 43:2610

9. Gayubo AG, Aguayo AT, Atutxa A, Aguado R, Olazar R, Bilbao J (2004) Ind Eng Chem Res 43:2619

10. Elliott DC, Hart TR (2008) Energy Fuels 23:631

11. Streitwieser A Jr, Heathcock CH (1985) Introduction to Organic Chemistry. Macmillan, New York

12. Weissermel K, Arpe H-J (1997) Industrial organic chemistry. Wiley-VCH, New York

13. Bhore NA, Klein MT, Bischoff KB (1990) Ind Eng Chem Res 29:313

14. Bhore NA, Klein MT, Bischoff KB (1990) Chem Eng Sci 45:2109 